\title{
DIE PROBLEEM VAN TOTALE AFSKAFFING *
}

Almal ken die ellende wat veroorsaak word deur die misbruik van alkohol en almal stem ooreen dat ons 'n ernstige beswaar het teen die misbruik van hierdie bedwelmende middel. Die euwel moet bekamp word en die wonderlike is dat dadelik gepraat word van totale afskaffing (prohibisionisme). Die vraag is: Moet ons dan maar die weg van die minste weerstand volg en is dit reg om byvoorbeeld van sulke maatreëls soos totale afskaffing gebruik te maak? Word alles nie hier te eenvoudig aangepak en moet die oplossing nie op 'n totale ander vlak gesoek word nie?

Ek wil die saak kort en duidelik so aan $u$ stel:

1. Misbruik hef nog nie gebruik op nie en matigheid beteken tog nie afskaffing nie. Soberheid mag nie vereenselwig word met myding nie. 'n Mens kan ook nie alle mense gelykskakel, en maak asof hulle almal oortreders is net omdat daar ' $n$ nogal geringe persentasie persone is wat misbruik maak van alkohol nie. Almal is nie swakkelinge nie en ons mag ook nie almal soos swakkelinge behandel nie. Die reël wat ons stel vir die behandeling van die swakkeling kan sekerlik nie die reël wees vir alle mense nie. Die vraag is: moet ons die hele sedeleer verander om aan te pas by die misbruiker en nie by die gebruiker nie? Dit sou 'n hele ontredderde toestand teweegbring. As ons God se Woord hier moet laat meespreek kan ons tot verrassende resultate kom. Dit sou in alle geval duidelik wees dat die oplossing van die drankvraagstuk nie lê in totale afskaffing nie maar dat spesiale maatreëls getref moet word vir dranksugtiges.

2. 'n Baie ernstige beswaar teen afskaffing word aan ons gegee in die Etiek. As soberheid gewin moet word, deur watter vorm van afskaffing ookal, het ons twee dinge wat nie bymekaar pas nie. Soberheid is 'n geestelike kwaliteit terwyl afskaffing dwang beteken en 'n verbod insluit. Matigheid word verkry deur gehoorsaamheid aan Gods Wet. Verbod is wanneer die owerheid tussenby tree om te belet dat ons ons sedelike vermoëns kan skerp tot gehoorsaamheid. Die vraag moet ons stel: Is ' $n$ mens wat nie aan alkohol verslaaf is nie omdat hy dit nie kan $k r y$ nie, 'n volwasse en mondige mens? Sodra hy alkohol kan bekom verdrink hy homself. Ons konklusie moet dus lui: Elke vorm van afskaffing het 'n nadelige invloed en is geneig om 'n geslag van fariseërs te kweek.

Die fout wat gemaak word is dat daar geen wesensonderskeid getref word tussen 'n persoon wat baie drink en 'n persoon wat matig drink nie. Ons lê die nadruk daarop, geen wesensonderskeid nie. Tog is daar ' $n$ wesensonderskeid. Die matige gebruiker is 'n mondige mens wat "nee" kan sê en sy mens-adel in onderworpenheid aan Gods Woord bewaak. As soberheid verkry moet word ten koste van vryheid, is dit te veel gevra.

Totale afskaffing moet dus afgewys word en as ons verant- 
woordelik wil handel, kan ons as Christene en Calviniste nie hierdie weg volg nie. Dit is negatief en die etiese weg pleit vir positiewe uitlewing en opvoeding van die hele mens as mens van God.

R. H. Johnson behandel die probleem en toon uit die Heilige Skrif aan dat afskaffingsmaatreëls strydig is met Gods Woord en bewys verder dat die afskaffingsidee gebaseer is op 'n onchristelike wêreldbeskouing. Hy stel dit so: Stoflike dinge kan nie op hulle self sleg wees nie, net persone kan sleg wees. Die propagandiste vir afskaffing redeneer so: Stoflike dinge is sleg en daarom is hulle nie deur God gemaak nie en daarom moet daar twee gode wees, 'n skepper van goeie dinge en 'n skepper van slegte of stoflike dinge. Vandaar dat hulle drank „,beduiwel" noem, die ,vervloekte ding".

Dit is nie die taal van die christendom nie. Laat ons Gods genade nie beledig deur aan die owerheid 'n taak te oorhandig waaromtrent ons ten onregte ons eie mislukking te kenne gee nie. Laat ons erken dat ons nie elke poging aangewend het om tot 'n oplossing, laat staan nog 'n korrekte oplossing, te kom nie. Dan sal ons gereed wees om 'n ernstige poging aan te wend en sal ons deur vermyding van hierdie dodelike valstrik van totale afskaffing, nog gestadiglik en eerlik probeer om 'n ware oorwinning te behaal oor die bedreiging van dronkenskap, en so vir die nageslag 'n dubbele seën verwerf.

Ds. J. V. Coetzee noem die volgende besware teen totale afskaffing:

1. Dit maak onder ons volk propaganda vir 'n heidense lewensen wêreldbeskouing.

2. Dit is revolusionêr en staan daarom al deur die Heilige Skrif veroordeel.

3. Dit tas gewetensvryheid van die mens aan en vernietig dit.

In die brosjure „Die kerk en die drank-vraagtuk" toon ds. C. W. M. du Toit ook aan dat prohibisie nie toegepas mag word nie. Dit is pure rookskerms en 'n totaal verkeerde middel. Dit word gedra deur die revolusiebeginsel. Die stryd teen afskaffing is die stryd vir vryheid sodat elke christen-mens kan handel en lewe na sy gewete. Vryheid is slegs vryheid as jy bereid is om aan ander dieselfde vryheid te gee as wat jy vir jouself toe-eien.

Ons moet dus hier konkludeer: afskaffing staan veroordeel omdat dit alle mense oor een kam skeer, die neiging het om alle etiese verantwoordelikheid weg te neem, om die geestelike volwassenheid te knak en om onverantwoordelikheid te kweek. Die vryheid om jouself te wees word jou ontneem. Nou kan 'n mens nie meer spreek van die adel van karakter en persoonlikheid nie, want ons het ons hoogste skat prysgegee wat God ons gege het, die eie trek van die beeld van God, ons vryheid.

\section{Die Bybel en gebruik van wyn}

In Bybelse tye was die gebruik algemeen om wyn te neem by maaltye en wyn is eintlik beskou as 'n daelikse voedsel. Dit was nie alleen iets wat behoort het by die adellike maaltyd nie maar by 
die gewone maaltyd; by die volk was dit ook bekend. Ons lees byvoorbeeld in Neh. $15: 18$ : „En wat vir elke dag berei is een bees, ses uitgesoekte stuks kleinvee en voëls - is berei op my koste, en elke tien dae allerhande soort wyn in oorvloed". Dit beteken dus dat die Israeliet gewoond was daaraan om by sy maaltyd wyn te gebruik. Misbruik is egter sterk veroordeel en die gevaarlike eienskappe in wyn word ook in die Skrif nie bedek nie. Ek lees in Spreuke 20:1: „Die wyn is 'n spotter, en sterk drank 'n lawaaimaker; en elkeen wat daardeur bedwelmd raak, is nie wys nie"'.

So ken die Heilige Skrif die matige en onmatige gebruik van wyn. Die onmatige vind ons byvoorbeeld by Noag, net na die ark op die berg Ararat grond gevind het om op te land en Noag druiwe geplant het en dit laat gis het en daarvan gedrink en toe dronk geword het. Die geskiedenis vind ons in Genesis 9.

Ek verwys in verband met die algemene gebruik van wyn nog byvoorbeeld na die voedsel vir die werkers van Hiram by die bou van die tempel. Let op die hoeveelheid wat hier aangegee word. Daaruit kan ons aflei dat wyn 'n integrerende deel van die werkers se maaltyd uitgemaak het. In 2 Kron. 2 : 10 lees ons hierdie woorde: „En kyk, ek gee as voedsel aan die houtkappers wat die bome kap, aan u dienaars, 20000 kor koring en 20000 kor gars en 20000 bat wyn en 20000 bat olie". Hieruit blyk dus dat dieselfde hoeveelheid gegee word in wyn as in olie en eweso in koring as in gars.

In die kultus maak wyn 'n belangrike deel uit. Hier verwys ek in die eerste plek na die Ou Testament en wel na Num. 18:12 waar ons lees: „Al die beste van die olie en al die beste van die mos en die koring, die eerste deel daarvan wat hulle aan die Here gee, dit gee ek aan jou". Hier word dus na die gisting van wyn verwys deur dit te noem mos. En verder Deut. 18:4 waar ons lees: „Die eerstelinge van jou koring, jou mos, en jou olie moet jy aan Hom gee". Hier geld dieselfde as by die vorige aanhaling. Duideliker kom dit voor in Neh. 20:37 waar ons dit lees: „Dat ons die eerstelinge van ons growwe meel en mos en olie sou bring vir die priesters na die huis van onse God". In Ex. 29:40 lees ons in verband met die daaglikse brandoffers: „Die lam met 'n tiende van 'n efa fyn meel gemeng met 'n kwart hin uitgestampte olie, en as dankoffer 'n kwart hin wyn vir die een lam". Dit is dus duidelik dat wyn in die erediens nie onbekend was nie want die erediens maak ' $n$ deel van die lewe uit en in die lewe aan tafel is die wyn so ' $n$ bekende deel dat dit eintlik net in ' $n$ tyd van armoede is dat daar nie wyn aan tafel gedrink is nie.

Die Nuwe Testament meld ook dat Christus self wyn gebruik het. Hier verwys ek na Matt. 26:29: „Maar Ek sê vir julle: Ek sal van nou af nooit meer van hierdie vrug van die wynstok drink nie, tot op daardie dag wanneer ek dit met julle nuut sal drink in die koninkryk van My Vader". Die woorde "nooit meer van hierdie vrug van die wynstok drink nie" laat duidelik blyk dat dit ook vir Jesus geen onbekende drank was nie. Buitendien het Hy dit ook self gemaak. Hier verwys ek natuurlik na Joh. 2 van vers 3 af waar ons die bruilof in Kana in Galilea het en waar Jesus die 
eerste wonderwerk van almal verrig het deur van water wyn te maak. Hier by die bruilof word gespreek dat daar nogal heelwat daarvan gedrink is. Ek verwys $u$ na die woorde in Joh. 2: 10: „Elke mens sit eers die goeie wyn op en, wanneer hulle goed gedrink het dan die slegste". As Jesus Christus dan ook by die erediens in die Nuwe Testament by die Heilige Nagmaal se instelling die wyn as een van die twee tekens gegee het, wil Hy daarmee te kenne gee dat ons hier te doen het met 'n adellike maaltyd en een waarin God verheerlik kan word deur al sy gawes wat hy aan die mens gee.

Nou is dit waar dat in die Heilige Skrif onthouding ook nou en dan voorkom, byvoorbeeld by Nasireërs, diegene wat besonderlik hulle lewe aan God wy. Ons weet ook dat Daniël, die profeet, hom besonderlik van wyn onthou het.

Ons kan hierdie gedeelte beëindig deur 'n paar konklusies te trek: In die eerste plek, die Heilige Skrif gee die vryheid om drank te gebruik, maar met inskerping van volle verantwoordelikheid. Ek wil hier nog verwys na 'n paar Skrifgedeeltes wat die verantwoordelikheid onderstreep. In die eerste plek Deut. 14:26 „Dan moet jy die geld gee vir alles wat jou siel begeer, vir beeste en kleinvee en wyn en sterk drank en vir alles wat jou siel van jou begeer, en jy moet daar eet voor die aangesig van die Here jou God en vrolik wees, jy en jou huis". In Psalm 104:15 hoor ons ook die lied van die Voorsienigheid van God en dan staan daar hoe die Here gras laat uitspruit vir die diere en plante tot diens van die mens: „om broodkoring uit die aarde te laat voortkom en dat wyn die mens se hart kan bly maak". Ons moet ook verwys na 1 Tim. 5:23 waar die apostel Paulus skryf aan sy seun Timotheus dat hy nie net water alleen moet drink nie maar ook 'n bietjie wyn ter wille van sy maag moet gebruik as middel, as geneesmiddel, vir herhaalde ongesteldhede.

In die tweede plek moet hierby herinner word dat die Skrif alle misbruik van drank as sonde veroordeel en dat die dronkaard die koninkryk van God nie sal beërf nie. Ons lees van hierdie vermaninge in die eerste plek Spreuke 23:20 waar die volgende staan: „Wees nie onder wynsuipers nie, onder die wat as vrate hulle hart ophaal. Want 'n drinker en 'n vraat sal arm word, en slaperigheid laat stukkende klere dra". In Jes. 5:11 hoor ons hierdie woorde: „Weë hulle wat vroeg in die môre klaar maak om sterk drank na te jaag, wat in die nag laat opbly terwyl die wyn hulle verhit". Die profeet Hosea, in sy vierde hoofstuk, vers 11, skryf so: „Hoerery en wyn en mos neem die hart weg".

Kom ons by die Nuwe Testament beluister ons in Ef. $5: 18$ hierdie apostoliese woord: ,Moenie dronk word van wyn nie daarin is losbandigheid: maar word met die Gees vervul". Dieselfde vind ons in Gal. 5:21 waar die haatlikhede van die werke van die vlees opgesom word en daaronder ook genoem word: „afguns, moord, dronkenskap, brassery en derglike dinge, waarvan ek julle vooraf sê, soos ek al vroeër gesê het, dat die wat sulke dinge doen, die koninkryk van God nie sal beërwe nie". Die Christen word ook vermaan om welvoeglik te wandel en by hierdie vermaning kom die volgende woorde voor: „Laat ons welvoeglik wan- 
del soos in die dag, nie in brassery en dronkenskap, nie in ontug en ongebondenheid, nie in twis en nydigheid nie. Maar beklee julle met die Here Jesus". In 1 Kor. 6:10 herhaal die apostel Paulus dat hoereerders ens. of dronkaards die koninkryk van God nie sal beërwe nie.

In die derde plek, die Heilige Skrif waarsku teen die gewoontevorming van drank en dit is 'n belangrike vermaning. In Num. $6: 1$ - 5 lees ons van die wet oor die Nasireërsgelofte waar hy vermaan word om nie aan enige iets te raak nie waardeur hy verlei sou kon word om hom te vergryp aan wyn. Hier word gesê dat hy hom van wyn en sterk drank moet onthou. Hy moet nie aan enige iets van die wingerdstok raak nie. Daar word sodanige bewerings gemaak dat hy geen asyn of druiwesap of vars of gedroogde druiwe of pitte of doppe van druiwe mag eet of drink nie. Hier word besonder duidelik die gewoontevorming of die verleiding tot gebruik van drank beklemtoon vir so 'n uitgesonderde persoon in besondere diens van die Here. Dit is eintlik dieselfde vermaning as wat ons verkry in 1 Kor. 8:13 waar ons lees: „Daarom, as voedsel my broeder laat struikel, sal ek in der ewigheid geen vleis eet nie, om my broeder nie te laat struikel nie".

In die vierde plek waarsku die Heilige Skrif teen die sonde om aan ander drank te gee om hom te verlei. Hier verwys ek na die profeet Habakuk hoofstuk 2:15: „Wee hom wat aan sy naaste drank gee, wat jou gif daarmee meng, en hulle ook dronk maak om hulle naaktheid te aanskou".

In die Nuwe Testament vind ons in die Timotheüs- en Titusbriewe hoe die apostel Paulus wat betref die opsienersampte dit as eis stel dat die ampsdraers bekend moet wees as manne wat nie verslaaf is aan drank nie. In 1 Tim. $3: 3$ word duidelik gestel dat so 'n ampsdraer geen drinker moet wees nie en in vers 8: so ook moet die diakens nie verslaaf wees aan wyn nie.

Dit is vir ons dus heel duidelik dat die Heilige Skrif aan die wyn 'n eerbare plek toeken binne die maatskaplike, binne die huislike en selfs binne die kerklike lewe. Maar dit is ewe duidelik dat daar benadruk word hoe die wyn ontaarding kan teweeg bring en dat dit iets is wat met groot omsigtigheid gebruik moet word.

Nou is dit bekend dat sommige Skrifverklaarders die bewering mak dat die wyn in die Skrif nie gegis was nie, daarom nie-alkoholies gelaai nie. Tog weet ons dat die Skrif verskil maak tussen wyn en sterk drank. Hoe die onderskeid daar gestel word weet ons nie maar wat ons wel telkens bewus van is, is dat die woord wat gebruik word in die Nuwe Testament vir wyn deurgaans gebruik word vir gegiste wyn. In Hand. 2 met Pinksterdag, die uitstorting van die Heilige Gees, is die verwyt juis die mense in die bo-kamer toegeslinger dat hulle dronk is en daarom in tale spreek. Maar Petrus het daarop geantwoord dat dit nog te vroeg was om dronk te wees van wyn. ' $n$ Mens lei hieruit af dat verwys is na mense wat gegiste wyn drink want anders kon daar tog geen sprake wees van dronkenskap nie. Dit vind ons reeds vroeg in die Skrif by Noag waar hy gegiste wyn gedrink het en toe dronk 
geword het en in sy dronkenskap verkeerd gehandel het. Die misbruik van drank word juis so skerp veroordeel en die koninkryk van die hemele juis toegesluit vir diegene wat hulle blywend misgaan aan sterk drank. Dit kon dus nie anders as gegiste wyn wees wat sterker alkoholies geword het by langdurige gisting.

\section{Gebruik en misbruik van alkohol}

Alkohol as stof, as materie, is amoreel. Dit is nie iets goeds nie en dit is nie iets kwaads nie. Sonde kan alleen ontstaan by menslike gebruik.

Alkohol het as sodanig ook wel nuttige gebruike veral in die chemiese wêreld. Dit word gebruik as oplosmiddel, by vervaardiging van chemiese stowwe, as brandsof, en dit het groot mediese waarde ook as ontsmetmiddel.

Sodra dit egter as verversingsmiddel gebruik word, word die prentjie heeltemal anders. Alkohol het 'n besondere uitwerking op die gestel van ' $n$ mens: as verdowingsmiddel, verswakking van die senuweegestel, 'n afstomping van verantwoordelikheid, aantasting van die breinsentra. Dit is gewoonte-vormend. Dit benadeel die wilsvermoë, selfbeheer, selfkritiek, en bring gebrek aan koördinasie. Dit is dus duidelik dat ons te doen het met 'n uiters gevaarlike vyand. Maatskaplike en huislike probleme kom natuurlik in hulle volle skerpte na vore. Dit is daarom dat alkoholverslawing seker een van die mees rampspoedige gevolge is van drankmisbruik. Die Heilige Skrif wys op die fisiese effek, naamlik in Spreuke 23:29 „By wie is ,ag"!; by wie is ,wee my"!; by wie is getwis; by wie is geklaag; by wie is wonde sonder oorsaak; by wie is dofheid van oë? By die wat láát opbly by die wyn, by die wat ingaan om gemengde drank te proe. Kyk nie na die wyn as dit rooiagtig lyk, as dit sy glans gee in die beker, glad na binne gly nie; op die end byt dit soos 'n slang en spuug gif uit soos 'n basilisk".

Voorts wys die Skrif op die ekonomiese gevolg van alkoholverslawing, naamlik armoede. In Spreuke $23: 21$ lees ons: „Want 'n drinker en 'n vraat sal arm word en slaperigheid laat stukkende klere dra".

In die derde plek wys die Skrif op die sedelike uitwerking naamlik soos dit uitkom in verbystering. In Jos. 4:11 lees ons die volgende woorde: "Hoerery en wyn en mos neem die hart weg". En as die hart weggeneem is dan is daar geen inwendige luisterpos om nog die Woord van die Here te verneem nie. Dit is die grootste verlies, die grootste wat van 'n mens weggeneem kan word.

In die vierde plek word duidelik gespreek in Jes. 5:12 van dit wat ons kan noem stompsinnigheid: „En daar is siter en harp, tamboeryn en fluit en wyn by hulle maaltyd; maar op die dade van die Here gee hulle geen ag nie, en die werk van Sy hande sien hulle nie". Dit is dus duidelik dat die oog gesluit is en die oor is heeltemal toe. Die grootste ellende is nie om blind of doof te wees nie, maar om oë te hê wat nie sien nie en ore wat nie hoor nie.

In die laaste plek moet ons nog noem die ontering van die 
beeld van God in die mens. Dan word alles prysgegee en vind 'n mens die meewarige toestand wat ons byvoorbeeld aantref by Noag. Die Skrif wy daaroor nie uit nie maar sê alleen dat Noag dronk geword het en naak in sy tent gelê het. Dit beteken dus dat daar geen eer meer is nie en dat die mens onkundig van sy eie toestand homself ontbloot selfs voor die oë van diegene wat dit so nie moes aanskou nie.

Die konklusie waartoe ons hier kom as ons spreek oor die gebruik en misbruik van alkohol is dat misbruik lei tot ruinering.

\section{Wat is 'n alkoholis?}

Gewoonlik word gespreek van 'n alkoholis in 'n enger of breër sin. Diethelm sê alkoholisme is 'n toestand waarin 'n persoon verkeer wanneer hy alkohol in so 'n mate gebruik het dat die voer van 'n suksesvolle lewe nadelig beinvloed word en hy nie in staat is om die uitwerking daarvan in te sien nie, of nie in staat is om sy gebruik van drank te beheer nie, ofskoon hy bewus is van die nadelige gevolge daarvan.

Clinebell omskryf ' $n$ alkoholis soos volg: „A person is an Alcoholic if one or more of his major adjustments in being, health, vocational, social or mental, is periodically or continuously hampered by drinking".

Esser noem alkoholisme: Alle gebruik van alkohol wat die sogenaamde sosiale drinkery te bowe gaan (alkoholisme in wyer $\sin$ ). Alkoholsug of ongekontroleerde drinkery is ' $n$ ekstreme vorm van alkoholisme (enger sin).

Allerweë word aanvaar dat ' $n$ persoon 'n alkoholis is wanneer hy beheer oor die gebruik van alkoholiese drank verloor het. Die simptome is:

a) Voortdurende oormatige gebruik van drank, met die daarmee gepaardgaande aftakeling van sy geestelike en maatskaplike verhoudinge.

b) Die alkoholis bevind hom eindelik in 'n toestand waarin hy slegs van alkohol lewe, weinig voedsel gebruik, byna voortdurend in meerdere of mindere mate onder die invloed van alkohol verkeer en sy verhoudinge in sy gesin, werkgewer en met naasbestaandes 'n breekpunt bereik.

Ons kan verskillende onderskeidinge hier tref en noem slegs drie: In die eerste plek die geleentheidsdrinker wat meestal matig met drank omgaan. Tweedens die strawwe drinker, wat dikwels erg onder invloed van drank verkeer, maar wat in 'n mate nog beheer het oor sy drankgebruik. Derdens die alkoholis wat geen beheer meer het nie, en eintlik voortdryf as 'n willose instrument. Jellinek onderskei vier fases van alkoholisme.

1) Die pre-alkoholiese fase

Elke persoon begin drink volgens die patroon van die maatskaplike omgewing waarin hy beweeg. Die latere alkoholis ondervind van die begin af aan ' $n$ sekere ontspanning in die gebruik van alkohol anders as die geleentheidsdrinker. Die latere alkoholis 
soek dikwels sosiale drinkgeleenthede op om bevrediging vir sy drang te vind. Stadigaan gaan die okkasionele drankgebruik in gereelde gebruik vir die ontspanning oor.

\section{2) Predromale fase}

Hier het ons algehele of gedeeltelike geheueverlies wat dikwels genoem word palimpseste. Die woord beteken eintlik dat eers iets geskrywe was op 'n blad en dat 'n mens dit geleidelik verdof het en toe het jy daar bo oor iets anders geskrywe. Veelvuldige palimpseste na middeimatige drankgebruik is tipies van die aanstaande alkoholis. Daar verdof iets in sy sielelewe sonder dat hy duidelik daarvan bewus is. Sy opvoeding word geleidelik vervaag en hy dryf eintlik weg van dit wat hy vantevore as beginsel in sy lewe gehad het. Sy tipiese gedrag is nou dat hy in die geheim drink, dat sy gedagtes gedurig vol is van 'n drang na alkohol, dat hy nie meer ' $n$ geselskapdrinker is nie maar dat hy vinnig drink, dat daar by hom 'n skuldgevoel ontwaak oor hierdie drinkery van hom, dat hy gesprekke oor drankmisbruik vermy, dat hy vergeetagtig word en dikwels protesteer as hy vermaan word oor sy drinkery, dat sy protes verder gaan en hy kwaad word hoewel hy weet dat hy skuldig is. In hierdie fase is hy nog besonder vatbaar vir sielkundige behandeling.

3) Kritieke fase

Hier kan ons verskillende reaksies onderskei by die alkoholis en ons som dit gerieflikheidshalwe maar op ter wille van inkorting van wat ons hier wil meedeel. Ons verkry verlies van kontrole oor drankgebruik en hierop volg dan dat so iemand sy gedrag probeer goedpraat, probeer rasionaliseer. Hy redeneer daaroor en probeer nog telkens die goeie op die voorgrond bring en praat lighartig oor die gevolge van drankgebruik. Die persoon verkry 'n skuldgevoel vanweë sy sosiale status en vanweë sy plek in die huisgesinslewe. Sommige word grootdoenerig en neem 'n aggressiewe houding in. Ander weer verkry 'n bittere spytgevoel wat ons duidelik moet onderskei van berou want dit is nie berou nie. Ons vind dat vriendskapsbande verbreek word juis omdat 'n inwendige mishae jou ontkoppel van vroeëre bande. Dit het 'n verdere funeste gevolg. Die persoon vereensaam. Hy verloor sy werk. Hy verloor belangstelling. Hy soek kontak met laerstaande persone op die leer van die maatskappy. Gesinsontwrigting tree in en liggaamlike siekte waardeur hy ook gevoel dat hy fisies tot veel minder in staat is as in die verlede. Soms vind ons hier nog selfbeklag en so 'n diepe selfmishaging dat dit selfs tot selfmoord kan lei.

\section{4) Kroniese fase}

Ook hier som ons net op. Die alkoholis het nou eintlik sy mens. syn en selfbeheersing verloor. ' $n$ Mens vind dat hy slaaf is van alkohol en dat hy voortdurend hunker na die beswyming wat alkohol met hom meebring. Nou tree langdurige dronkenskappe, selfs vroeg in die móre tot laat in die aand na vore en indien drank enigsins bekombaar is, is so 'n persoon nooit meer volkome nugter nie. 'n Mens kan begryp dat jy nou te doen het met iemand wat geestelik totaal afgetakel is en in morele verval moet kom. Hy gee niks meer om nie en die lewe bied vir hom niks meer nie. Hy besef 
dat alles verlore is en dat om 'n nuwe begin te maak eintlik vir hom verby is. Drank het by hom 'n obsessie geword en sy hele sielelewe is ingestel op alkoholgebruik. Ons kan hier spreek van 'n alkoholpsigose. Hier het ons nou die diepste ellende waarin so iemand kan verkeer. Al hierdie simptome kom nie altyd tegelykertyd tot ontwikkeling nie maar gee tog 'n aanduiding van die geweldige dieptes wat hier as afgronde voor elke alkoholis gaap.

S. J. Eloff dui in sy studie aan dat alkoholisme na sy wesensaard 'n religieus-etiese, psigologiese en medies-biologiese aspek het. Alkoholisme is dan vir hom 'n toestand waarin iemand verkeer wat vanweë die versteurende werking van alkohol op sy persoonlikheid geestelik sondig, psigologies versteurd en biologies siek is.

Die Heilige Skrif ken nie hierdie terme nie maar gebruik terme soos dronk, dronkaard, dronkenskap wesenlik in dieselfde sin. Die Heilige Skrif veroordeel dit as werke van die duisternis, werke van die vlees, ongeregtigheid, dit waaronder die aarde wankel.

\section{Alkoholisme: Siekte of sonde?}

Die opvatting dat alkoholisme ' $n$ siekte is, het in Amerika ontstaan en wel in die Yale Centre of Alcoholic Studies. By ons word dit gepropageer deur die Alcoholic's Anonymous, wat beweer dat alkoholisme veroorsaak word deur 'n bepaalde allergie, waardeur sommige mense anders reageer as ander. Of hierdie allergie fisies of sielkundig is, kan nie bepaal word nie en daarom kan niemand bepaal of ' $n$ persoon ' $n$ alkoholis gaan word of nie. Smith glo dat alkoholisme bepaal word deur 'n stofwisselingssiekte en dat die alkoholis se geslagsafwykings slegs die simptoom is van 'n versteur. de metabolisme. Wenger sê dat alkoholisme die simptoom is van geestesgebreke en dat hierdie gebreke behandel moet word voor die alkoholis gerehabiliteer kan word.

Die opvatting dat alkoholisme 'n siekte is, soek die probleem dus in die mens, in die spanninge van die lewe, en dit kan ons wel toegee. Tog moet gesê word dat meeste alkoholiste sekundêre verslaafdes is, wat hulle self geleidelik in hierdie stadium laat beland het. Natuurlik moet so ' $n$ persoon medies en psigiatries behandel word. 'n Alkoholis is siek omdat hy 'n alkoholis is en hy is nie 'n alkoholis omdat hy siek is nie. Die bewering dat so 'n persoon siek is, het die neiging om die drinker van al sy verantwoordelikhede te onthef. Die Kerkbode (12 Desember 1951) noem hierdie opvatting, naamlik dat alkoholisme 'n siekte is, 'n kunsgreep van die naturalisme wat wil weg doen met alle kwaad as 'n smet en skuld wat die mens aankleef deur sekere menslike handelinge terug te lei tot oorsake waaraan die mens geen persoonlike aandeel het nie.

Is alkoholisme dan 'n sonde?

Clinebell sê dat alkoholisme sy oorsprong in sonde het maar dit eindig in siekte. Pieterse sê: „Die opvatting dat drankmisbruik 'n sonde en alkoholisme 'n siekte is, is net maar 'n halwe waarheid, want alkoholisme is 'n direkte gevolg van drankmisbruik en moet dus as 'n sonde beskou word. Die mens in sy sedelike verantwoordelik- 
heid voor God, mag nie Gods beeld verander in die beeld van Satan nie. Die mens mag nie sy vryheid verander in losbandigheid nie. Alkoholisme is nie maar die mens se lot nie, maar sy skuld en dit is nodig om hom weer sedelik bewus te maak van sy hoë adel, sy heerlike roeping, hom te roep tot bekering om weer in Jesus Christus vrygemaak te word.

Rehabilitasie is nie die enigste taak en roeping nie, maar juis om hom te beweeg om terug te gryp na die beginsel en dit is die gehoorsaamheid aan norme wat pas by die Christelike lewenswandel, gebou op die enigste beginsel naamlik die Woord van God.

Dit is nou nie nodig dat ons wys op die totaal versteurde gemeenskapsverhouding wat deur alkoholisme teweeg gebring word nie. Ons weet hoe in die eerste plek die verhouding tot God totaal verbreek word. Ons weet hoe in die tweede plek die gesinsverband, die man-vrou-verhouding versteur word en eintlik totaal verbreek word en hoe die ouer-kind-verhouding totaal in verwarring kom omdat die kind nie weet wat daar eintlik aangaan nie. Ons weet hoe die verband met sy werkgewer totaal verbreek word en verder hoe daar ontwrigting kom in sy staatsverband, dat hy 'n gevaar word in die verkeer, dat selfmoord intree en so 'n persoon eintlik 'n totale las vir die staat geword het. Ons weet hoe die kerkverband daaronder ly en eintlik prysgegee word ter wille van die eie lam. lendigheid. Ons weet ten slotte dat die samelewing daardeur ly en almal eintlik so 'n persoon uitstoot uit hulle kring omdat hulle self met hom verleë is.

\section{Sedelike beroep op Christelike optrede}

Die Christen moet bewus wees van al die etiese aspekte wat hierdie gevalle van alkoholisme beheers en in optrede sowel as prediking en versorging moet sy hartlike meegevoel tot openbaring kom. Gelowiges moet soos volg te werk gaan:

a) Gelowige besoek en belangstelling, om voortdurend selfs in die

allermoeilikste omstandighede die hand te reik, misnoë en teleurstelling uit te spreek as gevind word dat so 'n persoon in 'n meewarige toestand verkeer, nie in sy dronkenskap nie maar daarna as hy weer aanspreekbaar word. Tegelyk moet tog nie vergeet word om ook bemoedigende woorde te spreek en die vreugde te laat uitstraal in jou woorde by die geringste merkbare verbetering.

Hierdie gelowige bejeëning, hierdie vriendskapsbetoon moet nie maar net nou en dan, maar gereeld voorkom sodat so 'n persoon bewus word van die opregte meegevoel en die innige begeerte om hom weer terug te bring tot die goeie lewe in 'n heerlike samelewing. b) Die naasteliefde moet prikkel, nie tot veroordeling nie, maar tot egte belangstelling. Dit is seker 'n uiters moeilike saak. Vir familiebetrekkinge is daar nog ' $n$ band, maar vir die naaste wat maar alte geneig is om maar liewer by so 'n probleemgeval verby te stap, is dit seker 'n veel gevraagde roeping.

c) Die alkoholis moet gehelp word om self te besluit, sy eie posisie dus voor God en sy naaste te begryp. Dit is uiters belangrik. Dit baat nie dat ons so iemand leer om volgens ons resep 
te lewe nie om die eenvoudige rede dat hy daarby nie meer kan aanpas nie. Hy moet homself oprig, die waarde van eie persoon besef en van eie menswees begryp.

d) Geneeskundige behandeling moet self verlang word. Ook hier is dit weer die moeisame weg omdat so 'n alkoholis homself eintlik voortdurend bedrieg, en onder die waan verkeer dat hy homself nog kan red. Dit mag voorkom dat iemand uit hierdie modder opstaan en weer 'n lewe lei wat God welbehaaglik is. Gewoonweg sou ons kan sê dat 'n ander mens so 'n persoon na so 'n beslissing moet help, voortdurend daaroor spreek, niks in die geheim doen nie.

Die vriendekring, wat mos al te dikwels by 'n alkoholis medealkoholiste is, moet vervang vord met egte christelike vriendskap, en dit moet volgehou word. Hier het ons seker die allermoeilikste taak wat opgelê kan word aan die Christelike maatskappy. Ons moet dit nie verontagsaam nie. Dit is sielkundig heeltemal waar dat iemand wat alkoholverslaafd is gewoonlik sy gesellige meenskap verkry by diegene wat saam met hom voortdurend daar verkeer. As hy nou van die drank weggeneem word, moet daar ander vriende in die plek van sy drank-vriende geplaas word. Hierdie vriende moet meer gesellige verkeer bring, moet so 'n persoon vreugde verskaf in 'n nuut gevonde lewe, 'n lewe van die wat veel meer welmenend is as die vriende wat vantevore sy vriende was. Dit moet gelowige vriendskap wees wat verhef en veredel en wat die adel van Gods kind te wees besonder sterk op die voorgrond bring.

e) Die beginsel van Gods Woord moet verkondig word en daarin word die mens nie net as die beeld van God geteken nie, maar veral as kind van God, in liefde aan God verbind, aan Jesus Christus. Dit is seker nie die moeilikste nie maar die mees verhewe doel van die christelike handreiking wat hier tot openbaring kom. Die hoogste adel is werklik dat ons ons verhouding tot God duidelik besef. Die lewe van die christen moet gesien word as 'n lewe wat nie 'n enkele dag sonder God en Sy Woord is nie. En die hoogste adel van die mens is tog werklik nie maar om sosiale wese te wees nie, maar die besef dat God die wêreld so lief gehad het dat Hy Sy Eniggebore Seun gegee het en deur Sy Gees het $\mathrm{Hy}$ die liefde in ons eie harte ook wakker gehou. 